University of Wollongong

Research Online

Faculty of Social Sciences - Papers (Archive) Faculty of Arts, Social Sciences \& Humanities

$1-1-2017$

The role of community sports clubs in adolescent mental health: the perspectives of adolescent males' parents

Diarmuid Hurley

University of Wollongong, dsh725@uowmail.edu.au

Christian F. Swann

University of Wollongong, cswann@uow.edu.au

Mark S. Allen

University of Wollongong, markal@uow.edu.au

Anthony D. Okely

University of Wollongong, tokely@uow.edu.au

Stewart A. Vella

University of Wollongong, stvella@uow.edu.au

Follow this and additional works at: https://ro.uow.edu.au/sspapers

Part of the Education Commons, and the Social and Behavioral Sciences Commons

Research Online is the open access institutional repository for the University of Wollongong. For further information contact the UOW Library: research-pubs@uow.edu.au 


\title{
The role of community sports clubs in adolescent mental health: the perspectives of adolescent males' parents
}

\begin{abstract}
Adolescent males are at relatively high risk of developing mental health disorders and show low rates of help seeking when mental health disorders arise. Parents are the primary source of support for adolescents and therefore have an important role in mental health promotion and prevention of mental health disorders. The aim of this study was to examine the perceptions of adolescent males' parents on the potential role of community sport clubs in adolescent mental health promotion. Forty-six parents of adolescent males took part in 10 focus groups to investigate parents' mental health knowledge, beliefs and attitudes, perceptions of the role of sport clubs in mental health promotion and disorder prevention, and factors that might promote or limit participation in (and effectiveness of) mental health-focused interventions. Thematic analysis revealed that parents had low levels of mental health literacy, were worried about the development of mental health disorders, but reported favourable attitudes towards receiving education on adolescent mental health. Parents also reported low confidence in their ability to discuss mental health with their adolescent and expressed mixed views on the role of the sport club in promoting positive mental health. These findings are considered in the context of developing mental health interventions that can maximise use of the unique youth sport environment.
\end{abstract}

\section{Keywords}

health:, perspectives, role, males', parents, community, sports, clubs, adolescent, mental

\section{Disciplines}

Education | Social and Behavioral Sciences

\section{Publication Details}

Hurley, D., Swann, C., Allen, M. S., Okely, A. D. \& Vella, S. A. (2017). The role of community sports clubs in adolescent mental health: the perspectives of adolescent males' parents. Qualitiative Research in Sport, Exercise and Health, 9 (3), 372-388. 
Running head: PARENTAL VIEWS ON MENTAL HEALTH PROMOTION IN SPORT

The role of community sports clubs in adolescent mental health: The perspectives of adolescent males' parents 


\begin{abstract}
Adolescent males are at relatively high risk of developing mental health disorders and show low rates of help seeking when mental health disorders arise. Parents are the primary source of support for adolescents and therefore have an important role in mental health promotion and prevention of mental health disorders. The aim of this study was to examine the perceptions of adolescent males' parents on the potential role of community sport clubs in adolescent mental health promotion. Forty-six parents of adolescent males took part in 10 focus groups to investigate parents' mental health knowledge, beliefs and attitudes, perceptions of the role of sport clubs in mental health promotion and disorder prevention, and factors that might promote or limit participation in (and effectiveness of) mental healthfocused interventions. Thematic analysis revealed that parents had low levels of mental health literacy, were worried about the development of mental health disorders, but reported favourable attitudes towards receiving education on adolescent mental health. Parents also reported low confidence in their ability to discuss mental health with their adolescent and expressed mixed views on the role of the sport club in promoting positive mental health. These findings are considered in the context of developing mental health interventions that can maximise use of the unique youth sport environment.
\end{abstract}

Keywords: Mental health promotion; intervention; mental health literacy; thematic analysis; youth sport 


\section{Introduction}

Mental disorders represent a significant contribution to the burden of disease in young

2 people worldwide (Costello, Egger and Arnold 2005). Approximately half of all mental health disorders begin to develop before the age of 14 years (Kessler et al. 2005), with an estimated $20 \%$ of all adolescents experiencing a mental health disorder in any given year (World Health Organisation, 2012). Young males in particular represent a group at high risk of developing a mental health disorder (Australian Institute of Health and Welfare 2011). In Australia (the focus of the present study) it has been found that $14 \%$ of adolescents aged 12 17 years have an ongoing mental health disorder (Lawrence et al. 2015). Importantly, adolescent boys are more likely to have experienced mental health disorders issues than adolescent girls, but are also less likely than adolescent girls to have sought professional help. Worldwide, as few as $10-15 \%$ of young people receive professional help when experiencing symptoms of mental health disorders (World Health Organisation 2005). The reasons that adolescents do not seek help include negative attitudes towards treatment and help seeking (Gonzales, Alegria and Prihoda 2005), poor mental health literacy (Burns and Rapee 2006) and high levels of stigma (Lawrence et al. 2015).

The high prevalence of mental health disorders in adolescence, in addition to low help seeking, indicate a pressing need for targeted preventive mental health interventions. Interventions that seek to benefit adolescent mental health also need to consider the family context (Sanders 2002). Research shows that adolescents with a mental health disorder report a preference for communicating about their mental health informally with somebody in their close social network (friends and family) and are more likely to seek professional help if recommended by these influential others (Jorm and Wright 2007, Offer et al. 1991). Moreover, adolescents (and young adults) suffering from a mental health disorder seek out their parents as their primary source of support (Jorm and Wright 2007) and often request 
their assistance in the process of seeking professional help (Logan and King 2001, Rickwood, Deane and Wilson 2007). Significant others, and parents in particular, should therefore have the knowledge and skills necessary to effectively assist the adolescent experiencing a mental health disorder (Mason et al. 2015). In particular, parents' mental health literacy can be crucial in the early recognition and treatment of mental health disorders for their children (Jorm 2012, Mendenhall and Frauenholtz 2015).

Mental health literacy refers to the knowledge, attitudes and beliefs about mental health and disorders, and the effectiveness of potential actions to benefit personal or others' mental health through symptom recognition, management and prevention (Jorm 2012, Jorm et al. 1997). Research has found that the mental health literacy of parents (concerning their child's mental health) is often poor, and that parents are not adequately prepared to help with a mental health disorder (Pescosolido et al. 2008, Jorm, Wright and Morgan 2007). In short, parents need more knowledge of mental health, mental health disorders and mental health resources (Chandra and Minkovitz 2006, Wang and Lai 2008). Parents' own stigmatising attitudes towards mental health can also influence their willingness to address their child's mental health and their intention to assist their child in seeking appropriate help (Fritz 2007). Low levels of mental health literacy among parents has negative consequences for adolescents including missed or delayed diagnosis of mental health disorders, non-treatment, unhelpful advice, and high levels of stigma (Mendenhall 2012, Perry et al. 2007). Interventions for adolescent mental health disorders that have demonstrated effectiveness in a family context include family support programs (Kuhn and Laird 2014) and parent-focused programs (Sanders 2002). To date, researchers have not investigated parental views on the potential role of sport clubs in adolescent mental health prevention. Community sport clubs represent a valuable resource for intervention among adolescent males and their parents. Around half of all children and adolescents participate in organised sport globally 
50 (Tremblay et al. 2014). In Australia, more than two thirds of all boys participate in some type of organised sport each year (Australian Bureau of Statistics 2012). The national prominence and large exposure of organised sport make it a potentially fruitful medium through which health professionals might aim to facilitate health behaviour change.

Adolescents who seek help for mental health disorders tend to prefer informal sources of support (Jorm and Wright 2007). A community sport club might provide an environment for adolescent mental health promotion and disorder prevention through the support network of parents, sport coaches, teammates and important others. Coaches are in a position of care, responsibility and trust, and can positively influence adolescent mental health (Donovan et al. 2006). Coaches themselves recognise that they have an important role to play in promoting and protecting the mental health of their athletes but are often concerned about their lack of knowledge and skills, and the expectations of their role (Mazzer and Rickwood 2015, Mazzer, Rickwood and Vanags 2012). Research on the role of the coach in youth mental health promotion is limited, but a study providing mental health first aid training to youth sport coaches in Australia was found to increase coaches' confidence and ability to assist a young person developing or expiring a mental health disorder (Pierce, Liaw, Dobell and Anderson 2010).

Friends (and in the case of a sport club, teammates) are also an important source of support throughout adolescence (Rickwood, Deane, Wilson, and Ciarrochi 2005) and can contribute to adolescents' intention to seek help or engage in treatment (Gulliver, Griffiths and Christensen 2010). A recent evaluation of Mental Health First Aid for 16-18 year olds increased confidence and intentions to help as well as reduced stigma (Hart et al. 2016). Importantly, this program emphasised seeking support and advice of trusted adults, including parents. Coaches have also reported that they encourage young people to talk to their parents about mental health (Mazzer and Rickwood 2013). Organised sport might be a useful setting 
in which to engage parents, as parents have a central role in adolescent sport participation (Fredrick and Eccles 2005). Parents have a natural role in providing support to their child before, during and after sport participation (Tamminen and Holt 2012). Indeed, a recent pilot study of parental education found that sport was a particularly useful environment to target parent behaviours and parent-adolescent relationships (Dorsch et al. 2016).

Participation in sport is associated with a range of psychosocial benefits (Bradley, Keane, and Crawford 2013, Eime et al. 2013) and can protect against the development of mental health disorders in children (Vella, Cliff, Magee and Okely 2015). Unfortunately, while research has demonstrated the potential benefits of sport participation for mental health, the mechanisms through which sport can be used as a vehicle to support positive mental health behaviour are unclear (Carless \& Douglas 2008). A recent review by Liddle et al. (2016), reported that only $11 \%$ of sport organisations in Australia have engaged in campaigns that target members' mental health. These campaigns have often lacked an evidence based approach and robust evaluation. Therefore, there is a need to explore the potential for sport organisations to take a more active role in the promotion of mental health and prevention of mental health disorders.

The current study qualitatively investigated sport parent perspectives on the role of community sporting clubs in adolescent male mental health promotion. A qualitative approach was taken as this enabled a deeper exploration of parents' experiences, knowledge and attitudes regarding the potentially sensitive topic of adolescent mental health (Carless and Sparkes 2008). This study aimed to investigate: (i) parents' knowledge, attitudes and beliefs about adolescent mental health (i.e., their mental health literacy); (ii) parents' perceptions of the potential role of sport in mental health promotion and disorder prevention; and (iii) parents' perceptions of the factors that might promote or limit participation in (and 
effectiveness of) an adolescent mental health intervention delivered through community sport.

\section{Method}

\section{Philosophical Orientation and Design}

Stemming from a relativist ontological position, this study adopts an interpretivist approach in understanding parents' knowledge, attitudes and perceptions (Guba and Lincoln 1994). In this respect, we take the view that reality is subjective, differing from one person to the next even under the same phenomenon or circumstances. The interpretive approach is typically inductive with findings emerging from the data (Cohen, Manion and Morrison 2007) through interaction between the researcher and participants (Guba and Lincoln 1994). Methodological considerations for an interpretive approach seek to understand not only the individual, but also their social and cultural environment (Creswell 2009). As such, it is important to understand multiple views on how parents comprehend and experience mental health, as well as how they perceive their role in the community sport club, and the club's role in mental health promotion.

Focus groups were chosen as the most appropriate method to generate discussion and gain in depth responses from sport parents. This method enables participants to share, reflect and discuss diverse ideas and opinions, which can lead to richer data than individual interviews (Harwood, Drew and Knight 2010, Hefferon et al. 2013). Focus groups can also provide a safe space for participants to discuss sensitive topics, such as mental health, thereby facilitating disclosure (Carless and Sparkes 2008). Focus groups have been frequently and effectively used in exploratory studies and in studies with sport parents (Harwood, Drew and Knight 2010, Sparkes and Smith 2013). 


\section{Participants}

Sport clubs across the six most popular sporting codes by registered adolescent male player numbers (Swimming, Cricket, Tennis, AFL, Soccer and Basketball) in the Illawarra and South Coast region of Australia were contacted via telephone and email, and invited to take part. Parents of adolescent male athletes were then purposively recruited. In total, 46 parents took part in 10 focus groups. The majority of the participants were mothers $(n=32$, 69.5\%), with 14 fathers taking part. Participants ranged in age from 31-63 years (mean age = $46.3 \pm 6.0$ years $)$, and had an average of 2.5 children. More than half of participants $(56.5 \%)$ had completed some form of tertiary education.

\section{Procedure}

Following ethical approval from a university research ethics committee, sports clubs were contacted through the club president and/or personal contact with other club members. Upon gaining the support and consent of each club, parents were approached during youth training sessions or competitions and informed about the purpose of the study. This process involved informal conversations about the project (and the opportunity for parents to ask questions) and the provision of an information sheet. Parents expressed an interest in participating in a focus group by providing their contact details. Parents were then contacted via phone or email to arrange a convenient time and setting for the focus group to take place. Focus groups were facilitated by the lead author as well as by two other members of the research team who had experience in focus group research. Face-to-face and telephone meetings, as well as email communication, ensured that all facilitators were able to adopt a consistent approach on any issues relating to facilitation, for example, ensuring that essential questions relating to the role of sport in mental health were asked. Focus groups took place at a university or local sport clubs. 
The duration of each focus group ranged between 40 and 100 minutes (mean $=64.0 \pm$ 15.5 minutes). An average of 4.6 parents took part in each focus group, ranging from two to

10. Participants from the same community sport clubs were purposively grouped for

familiarity so as to facilitate discussion. The start of each focus group was used by the involvement in sport and the local sport club. At the end of each focus group, participants were asked if they had any other comments or suggestions they would like to share. All focus groups were digitally audio recorded and later transcribed verbatim by a professional transcription company. Upon completion of the focus group, parents were thanked and presented with a $\$ 20$ gift voucher.

\section{8}

\section{Discussion Guide}

A discussion guide was developed with questions divided into four sections (see Appendix A). The first section investigated family dynamics, that is, the nature of the family environment and relationships, and general beliefs about mental health. The second section explored parents' knowledge of, and attitudes toward, adolescent mental health and helpseeking (i.e. their mental health literacy). The third section examined parents' perception of the role of the sport club in mental health promotion. The final section explored the potential barriers and facilitators for sport parents to being involved in a mental health intervention.

\section{Analysis}

Data were analysed inductively through the guidelines for thematic analysis outlined by Braun and Clarke (2006). In the first phase, the lead author engaged in the process of indwelling (Maykut and Morehouse 1994) by reading each transcript several times and becoming immersed in the data. Through this practice, the lead author became familiar with key messages specific to each focus group and potential trends or common factors across focus groups. Second, initial codes were developed by the lead author to ascribe basic 
meaning to the data. In the third phase, conceptually similar codes and corresponding raw data extracts were identified, sorted and grouped together where appropriate to form higher order themes. In the fourth phase, higher order themes were reviewed and revised. An iterative process was used throughout data analysis whereby themes generated from the data were revisited, by examining themes in context, to enable better understanding, better fit and more refined descriptors (Srivastava and Hopwood 2009). In the fifth stage, these higher order themes were organized into descriptive categories which served to represent a coherent account of the meaning of the data. For example, initial codes were assigned to describe the interaction and social support networks of parents through the sports club. Further analysis revealed that parents identified a sense of community in the sports club, a theme which encapsulated the nature and perceived benefits of sport club membership. Codes within this theme were homogenous in nature, while the theme itself was related to but heterogeneous to other themes in the overarching descriptive category (see Table 1).

\section{Enhancing Trustworthiness}

To enhance trustworthiness - the process of ensuring methodological quality and credibility in qualitative research (Shenton 2004) - the guiding principles of contributory, rigorous, defensible and credible interpretivist research are discussed (Spencer et al. 2003). First, the current study contributes to and enhances understanding of parents' mental health literacy and their perceptions of the role of community sport clubs in adolescent mental health, findings which can also be used to inform the development of future interventions. In addition, a thick description (Geertz 1973) of the participants and the social context and culture of community sport clubs enables the reader to judge for themselves about the appropriateness of transfer or generalisability of findings. Next, a detailed and transparent account on participant recruitment, data collection and analysis is provided, addressing the need for rigorous and defensible research. Furthermore, the credibility of the findings are 
supported by the use of peer debrief (Creswell and Miller 2000). Peer debrief was undertaken with other members of the research team at several stages, both formally and informally, throughout data collection and data analysis. Regular formal meetings focused on issues including the running of focus groups and which questions generated more or less discussion among parents, as well as discussions on the core themes emerging from the data. Through this process, the lead author was questioned on, and attempted to provide justification for, the development of themes and descriptive categories. In this way, the lead researcher was led to reflect on his predispositions, (e.g. as a mental health researcher) and interpretations.

\section{Results}

Thematic analysis resulted in the development of four main descriptive categories containing 14 themes relating to parent mental health literacy, parent perceptions of the role of sport in mental health promotion and of facilitators and barriers to intervention participation and effectiveness. These findings are reported in Table 1 and presented in detail below.

\section{Experience and Exposure to Mental Health}

At least one parent per focus group had direct experience of mental health disorders.

Direct experience includes personal, familial or significant others' mental health experiences, while exposure is used to describe wider societal or public examples of mental health disorders. Previous experience and exposure to mental health disorders influenced parents' mental health knowledge and attitudes and was the main trigger for discussing mental health as a family.

Parents thought that 'the mental health situation is quite big now and it's everywhere' and that 'we all have or know someone that is mentally unwell' (Swimming Parent). One 
parent gave an example of her children's exposure to mental health disorders as an opportunity to raise awareness about such issues:

12 months ago if I had asked my boys they wouldn't have known, they wouldn't have known what I'm talking about. However now with those experiences that they've seen firsthand ... The high profile ones, they know now. So if I was to ask them, “How's your mental health?” they'll know exactly what I'm talking about. (Cricket parent) Many parents reported that they addressed mental health indirectly with their children. When their children came to them with issues, these served as prompts to talk about subjects related to mental health: Confidence and self-esteem comes up a lot more than...I think sometimes the kids will come home and they'll talk about another person that they encountered at school or ... and so that's often a prompt for ... a conversation starter to be able to then bring it in, but I wouldn't necessarily bring it up, unless-they normally bring it up. But as soon as they do, it's like that teachable moment. (AFL Parent)

Attitudes toward mental health and help seeking. There were mixed attitudes surrounding mental health and accessing mental health services. Mental health was predominantly described by parents in terms of mental disorders, with depression and anxiety most frequently mentioned. However, a more balanced view of mental health, incorporating a person's state of mind and well-being also featured in a number of focus group discussions. Parents that had experience in seeking help for themselves or for their children, raised a number of issues in regard to accessing services, including the cost and quality of those services. Parents living in more isolated areas highlighted the lack of services in their area. 
Parents agreed, however, that getting help is important and beneficial for their children, as this experience 'transfers to their adult lives and they've got no problem with finding help'.

Parents also talked about finding the right kind of help, the right fit for their family: I've always had the family doctor. There's that history there. I think that's really important. I wouldn't just suggest, hey, let's rock up at the medical centre and say, "You're having a breakdown, give us some drugs," like I don't think that's going to work. I think it comes back to the doctor knowing you as a person or knowing the child and coming through the ranks. (Swimming parent)

Stigma. Parents thought that while a stigma around mental health and help seeking still existed, attitudes had become less stigmatising over time. Mental health was still 'the sort of thing you probably would talk about in closed doors, not when you're in company with other people'. One parent described the experience of a mother she knew seeking help: There was some issues and her child needed some counseling and I said, "You can get a mental health referral and rebates, Medicare." She said, "I don't want that to be on his record anywhere for when he becomes an adult that he's got any mental health issues," so I think there's still a stigma... She saw it as a black mark on her child's medical history. (Soccer parent)

Other parents, especially those with help seeking experience, were not as concerned about appearances when seeking help and thought that 'there's no shame in sending someone to a psychologist anymore - that's what you do' (Cricket Parent).

Need recognition. Most parents admitted that they didn't think about mental health until it became an issue. The comment below represents the predominant views of parents: I think generally most parents will think, “If they're not broken, then we don't need to fix it." If you're not aware of what's going on, if you're not aware of the signs and the child hasn't indicated anything to you, I don't know whether this would mean 
anything. But if you suddenly became aware then I think as a parent you would do what you need to do in order to help. (Tennis parent)

Parents did, however, recognise that they had an important role and responsibility in their child's mental health as emphasised by one mother:

I like that this takes it back to family focus, not to the, "Let's teach them this at school", because if the family knows it and practices it and understands it, then their children are more likely to grow into adults who know it and practice it and understand it, and that becomes a positive cycle. (AFL parent)

\section{Dealing with Mental Health Disorders}

The majority of parents were uncertain and felt ill-equipped in how to spot a mental health disorder in their child and how best to respond. Almost all parents were interested in learning about the warnings signs of a mental health disorder in their son versus what could be considered normal teenage behaviour, as well as what to do and where to go for information.

Concern about mental health disorders. Many parents expressed a fear or concern about discovering or missing the development of a mental health disorder in their child. It was something that played on parents' minds, especially for those with previous direct experience:

For me, coming into adolescence because my eldest is 14 and then a 13 year old. They're both boys. That really concerns me. We've got a family history of mental illness so just being really constantly through my head I'm thinking, "Okay is this issue that he's talking to me about, is this just an issue that I need to deal with today or this week or is this something I need to look more deeply into?" (Soccer parent) 
How to tell. Parents in all focus groups raised the issue of symptom recognition for mental health disorders, specifically outlining the difficulties they face in telling the difference between "normal" teenage behaviour and the signs of a mental health disorder: I think the most confusing thing about this is that a lot of these signs ... the difficult part is actually knowing what is normal adolescent behaviour and what's actually a sign of mental health, because every single one of these signs is present in a normal adolescent that isn't suffering from any mental health as well. (Mixed sport parent) Parents also thought that the adolescents themselves could be confused about their feelings, about what was "normal" for them to experience. A few parents argued that the nature of the parent-child relationship would enable them to spot an issue developing: 'So knowing your kids well and knowing their character we'll be able to identify more whether it's something to do with mental health, or they've just had a bad day or something has happened' (Cricket Parent). Finally, parents also spoke of talking about teenage behaviour with other parents and the benefit of gaining others' perspective.

What to do. Some parents had direct experience in dealing with mental health disorders, but many did not know how they would respond if an issue arose in their child. Lack of knowledge about concrete action steps contributed to parents' uncertainty. As one tennis parent expressed: “It's something I think as parents we're quite anxious about, because there's no hard and fast rules. I think a lot of people don't know what's the best way to respond."

Some parents shared what they thought they would do if they needed help. This involved having a conversation, listening to what their child had to say, creating a loving environment and offering advice and support:

Just bringing them in and saying, "I'm really worried about you. We are really worried about you. This is what we'd like to do. Are you okay that we go and talk to 
someone else? Because we've noticed a change." So that kind of stuff. (Basketball Parent)

Parents also said they would seek external help, either through professionals such as a

school counsellor or general practitioner, or through internet searching.

\section{Role of Sport in Family Life and Mental Health}

Sport participation was reported to have a meaningful influence on family life.

Parents thought that sport offered many benefits for their children, brought them together as a family, and gave them access to a wider social support network. Many of the parents, and in particular fathers, also acted as coaches or volunteers for their child's sport teams.

The sport club as a community. The positive influence of the sporting club extended beyond the playing arena, providing a wider support and social network for parents and their sons. The community feel of the sport club was emphasised most by swimming, AFL, and basketball parents. Within the sport club, parents and coaches were looking out for each other's children and their well-being:

I suppose as it goes you start to open your eyes at how important sport is and why we put ourselves through this all the time for the kids. Because the more you go around, the more it expands, doesn't it? If they are seeing other players as role models then all the other players' parents also then start watching out for the same kid. (AFL Parent)

The club was a place where parents could come together, offer an outside perspective and advice, and support one another:

Well I think the sports clubs are positive role models with families. You all get together with your family, come to the sport club, you're around other families. It's a positive environment. I guess, when we all get together, we discuss parenting and different strategies with our kids. We give each other suggestions and support that 
way. I think that's what the sports clubs provide, it's a place to come together and you kind of can love each other's children and become a bigger family. (Basketball Parent)

Role of sport in mental health. There was less agreement about whether the sport club was a place that could facilitate mental health intervention. Some parents did not think that a sports club was an appropriate place to talk about or try to influence mental health: 'I don't think it's the role of a sports club to educate parents about youth's mental health. I don't see it as the responsibility of a sports club to do that (Swimming Parent).' Parents also thought that by focusing on sport, some non-participating families, who may be in most need, would miss out. A small number of parents pointed out that sport can sometimes be the cause of mental health disorders in children. They alluded to issues arising in their own children from dropout, injury, competition and pressure. Only one parent referred specifically to the culture of sport and sport clubs as a potential barrier to mental health promotion:

If you are going after sport as a way to connect with kids, I imagine that what you are up against is a culture of decades and decades of this macho sport thing...I think there's some really big stereotypes that you're going to have to knock over before you get an easy way in (AFL Parent).

However, some parents talked about the benefits of being involved in sport, how it makes children feel good and have fun, the clear links between physical and mental health and how sport teaches valuable life skills. Parents saw the potential for promoting positive mental health in sport, particularly through the natural social support networks that exist in community sport clubs: 
These guys, many of them will be okay because they have their sport and that's so important to their mental wellbeing, but it might encourage them to reach out to someone else to open the door. (AFL Parent)

It might be the sporting involvement extends that support network around the child so they've got a variety of places that they can seek out some support. If it's not working at school then maybe they can get it through the sports club. (Tennis Parent)

\section{Barriers and Facilitators to Sports Based Intervention}

Parents gave their opinions on what they would engage with as part of a mental health intervention in sport, how best to promote an intervention to sport parents, and the potential barriers that could limit intervention participation and effectiveness.

Addressing parent needs. Parents needed education and information on mental

health with an emphasis on how to recognise symptoms of a mental health disorder and how to respond. Parents wanted succinct, concrete, takeaway information: 'It'd have to be really basic, okay, these are the sort of things you might look for in these age groups and these are the sort of places you would go if you want help' (Tennis Parent).

So if there's something wrong, where am I going to go? Not just, "Make a safe, loving environment," that's nice because we do that all the time. What I want is some action from the health professionals to get assistance and how do I know where to go for that? (AFL Parent)

Communication was an issue that also came up across focus groups. Parents not only wanted information on mental health but also wanted to know how to talk about it with their adolescent, to be able to check in and normalise talking about mental health. They needed guidelines and strategies to start the conversation and to overcome difficulties they've experienced, particularly in communicating with adolescent boys. Parents also expressed a desire for choice in how they received and interacted with the intervention material: 
So I think if you've got strategies in pictures, in words, in video, that gives everybody the opportunity to go... You know, you're telling me, but if you go here's a choice and I wanna do that one - then I'm in control. (AFL Parent)

Furthermore, parents conveyed that it was important that the intervention was not exclusively negatively focused but that it also contained a message of positivity, proactivity, hope and well-being.

Reaching and engaging parents. For most sport parents, the method of intervention promotion and delivery considered most suitable and convenient was electronic (either through computer or phone). The information needed to be easily accessible to parents and not require too much effort to find:

Yes, I'd probably be more online. So if there was a hub of information, say mentalhealth.com or something, so you knew that was a starting point for getting information, and then directing you to the services that were accessible more locally, I guess that would be helpful. (Tennis Parent)

Social media, particularly Facebook, was mentioned by a number of parents as a method of engagement: 'So social media, internet and all of that access, there's got to be a way of introducing it and making it more available to the parents as well.' Some parents preferred to have access to the information at convenient locations such as at the sports club or other places in the community where they and other parents regularly are. Parents thought multiple channels could be used in intervention promotion: I always think if you've got a particular message, if you sent it at the same time in a range of different ways, it's the same information in a newsletter, in an email, on Facebook, then I would be likely to see one of those methods and I would probably read it. (Tennis Parent) 
Parents also talked about the informal, social support networks within sport clubs and

how these could be used to spread messages and awareness among parents, both online and in person: 'We do that the most don't we, "Heard about this thing called Headspace", because we talk more afterwards and it will be something like that, will have just stuck in your head' (Basketball Parent).

Barriers to participation. A lack of time was one of the main barriers to participating in an intervention. Many parents doubted whether they would attend something in person because of the inconvenience and amount of effort it took. As one parent reported: That's a problem with (in person) meetings, is you then have to go, "I've got to get a babysitter, I've got to get dinner done," I've got to do that sort of stuff...An obligation. It's being obligated to do something. (Tennis parent) Need recognition was also relevant to engagement. If parents did not observe an issue in their child, they would not have an interest in looking for information. Convenience and ease of access to information was another important factor for parents' willingness to participate.

\section{Discussion}

The purpose of this study was to qualitatively investigate the mental health knowledge, attitudes and beliefs of parents of adolescent boys, their perceptions of the role of sports clubs in mental health, and the facilitators and barriers that might promote or limit the effectiveness of a mental health promotion intervention. Thematic analysis of focus group data revealed that parents had generally low levels of mental health literacy, were worried about their adolescents developing a mental health disorder, and wanted information and education on mental health. They also expressed mixed views on using sports clubs as a vehicle to promote positive mental health. These findings might be of value to mental health 
professionals interested in using sport as a vehicle to promote positive mental health in adolescent males.

Direct experiences of mental health disorders and accessing mental health services were not uncommon in the current parent sample. This is not surprising, considering previous research has shown that up to $75 \%$ of the general public who experience dealing with mental health problems of friends or family, try and provide support (Reavley and Jorm, 2012). Past experience was important for parents' knowledge and attitudes of mental health and help seeking, supporting previous research findings (Teagle 2002, Verhulst and Van der Ende 1997). Overall, levels of mental health literacy in parents appeared low, which is consistent with previous research (e.g., Jorm, Wright and Morgan 2007, Pescosolido et al. 2008). Further examination of this finding in relation to the various components of mental health literacy (as described by Jorm et al. 1997) is necessary. First, the majority of parents had limited ability to recognise the presence or development of mental health disorder symptoms in their adolescent. Indeed, the most frequently raised point by parents was that of being unable to distinguish between possible symptoms and that of "normal" adolescent behaviour, an issue also reported in other research (Bussing et al. 2003, Boulter and Rickwood 2013).Second, our findings showed that parents did not have sufficient knowledge about help seeking services and treatment options, and crucially lacked the capacity and confidence to effectively intervene and help. Third, parents did demonstrate knowledge of effective selfhelp and supportive strategies (as described by Morgan and Jorm 2009) in their actions with their children.

Fourth, in investigating attitudes to mental health and help seeking, parents, predominantly viewed mental health in terms of mental health disorders, consistent with past research on public beliefs about mental health (Henley et al., 2007). There was some perception of public stigma around mental health and seeking help, but these attitudes were 
not endorsed by most parents, in contrast to previous findings (Dempster, Wildman and Keating 2012). Family history and experience of mental health was also related to parents' willingness to seek help and access treatment services, in line with previous research (Verhulst and Van der Ende 1997). Importantly, our findings show that many parents saw it as their responsibility to help their child as well as to protect their mental health.

Furthermore, parents were generally in favour of changing perceived stigmatising attitudes in society, open to accessing help services and treatment, and wanted to normalise discussion around mental health, especially in adolescent males.

In examining sport as a potential vehicle for mental health promotion and disorder prevention, opinion was mixed as to whether the sport club was the most effective or suitable setting for a mental health intervention. Parents did see some benefits to their son's wellbeing from sport participation, primarily the supportive social environment of the sport club community. These findings are consistent with those found by Wiersma and Fifer (2008) in their study on parents' perceptions of the benefits of youth sport. The youth sport setting also provided an opportunity for parents to meet and interact with other parents and to be part of a community - benefits also reported in other studies (Harwood and Knight 2015, Wiersma and Fifer 2008). In addition, our findings show how the sport club provided a forum for parents to talk, share advice and discuss parenting as well as look out for each other's children. Parents also acknowledged that sport can contribute to the development of mental health disorders in young athletes, citing negative experiences such as injury, pressure and burnout-impacts reported previously in the youth sport literature (Merkel 2013).

\section{Limitations}

The present study has several limitations. Parents of male adolescents were purposely sampled from community sporting clubs. However, parents who volunteered to take part in focus groups may not be entirely representative of the wider sport parent population. Parents 
who might benefit most from this intervention and might be at greatest risk (e.g., those with high stigma toward mental health disorders), might have been less willing to participate - an engagement issue reported previously in the literature (Snell-Johns et al. 2004) and mentioned by parents in the current sample. The study sample did reveal that at least one parent in each focus group had direct experience in dealing with mental health disorders. Furthermore, over two-thirds of the parents were mothers. It has been found that women have higher levels of mental health literacy than men (Pescosolido et al. 2008) meaning the mental health literacy needs of the current sample might differ from those of a more gender balanced sample. Future qualitative research, using innovative methods, could take into account variations in responses by gender and other demographic variables (see Onwuegbuzie, Dickinson, Leech and Zoran 2013 for description of this method).

Nevertheless, as was found in the current study, parents (regardless of gender), perceived a need for mental health information and education.

Another potential limitation, especially in discussing a topic that is something potentially personal and sensitive, is the tendency to respond in a manner that is socially desirable. For example, parents might be unwilling to disclose information about mental health disorders in their child because they do not want to be thought of as a bad parent (see for example, Saval et al. 2010). It should be noted that in the current study, most parents were quite candid and open about their family's mental health experiences.

\section{Implications}

To our knowledge, this is the first study to examine the potential for a mental health promotion intervention for parents to operate through community sports clubs. This study identified a number of areas for intervention content development and delivery. First, it was found that parents lack basic mental health literacy and are generally open to receiving information and education on mental health and help seeking. Previous research has also 
revealed parents' need for mental health knowledge and information (Boulter and Rickwood 2013, Cohen et al. 2012). Findings from the current study add to this knowledge base by identifying particular gaps in parents' knowledge. Moreover, interventions should target symptom identification, build on parents' knowledge of effective self-help strategies, and provide clear guidelines and strategies on how to respond to and manage adolescent mental health disorders, and how to communicate about mental health with adolescents. This would serve to ease parents' concerns about their current lack of knowledge, skills and confidence to support and protect adolescent mental health.

Second, this study revealed important information about parents' attitudes and beliefs about mental health. Despite parents' concerns about adolescent mental health disorders and mental health carrying mostly negative connotations, there was a clear desire expressed by parents to reduce the stigma and increase awareness around mental health disorders. Parents also promoted the importance of help seeking, and wanted to normalise talking about mental health. Interestingly, parents perceived that they had a responsibility to support adolescent mental health but felt that they had deficits in their knowledge and skill base. However, it is evident that strategies to engage more parents will need to target a lack of perceived need, as this perceived responsibility only appears to apply in reacting to adolescent mental health disorders. Parents, who do not think the content or message is relevant for their adolescent in the immediate future, might be less likely to engage. Other barriers to participation, according to parents, were a lack of time, inconvenience, and the ease of access to information - all barriers that have been observed in parent programs (Friars and Mellor 2009). As argued by Mendenhall and Frauenholtz (2015), mental health literacy interventions should be tailored to the mental health literacy levels of participants to have maximum impact. Past research demonstrates that utilising a multilevel prevention approach with parents, as opposed to a universal one size fits all approach, would improve intervention 
reach, impact and effectiveness (Kuhn and Laird 2014). Our findings suggest that this approach should take into account parents' past mental health experiences, the unique parentadolescent relationship, current levels of mental health literacy, perceived barriers to participation and preferences for information content and delivery. In this way, an intervention can meet the varying needs of parents by raising awareness of the importance of a proactive role in adolescent mental health for those parents who do not perceive a need, while also offering useful information on mental health and help seeking to those parents who do.

Based on parents' feedback, interventions might use multiple delivery channels to enable greater engagement, choice and reach. The majority of parents preferred online methods as their primary form of receiving information on mental health. Importantly interventions, should they utilise online channels, should not negate the importance of the sport club community. A combined focus on online, as well as in person, social networks among parents in the same sport clubs may aid intervention promotion and engagement. Third, the current study revealed important new information about the potential role of sport and the community sport club in the promotion of positive mental health, from the perspective of parents. The sport club was not seen as having an explicit role in mental health promotion. The majority of parents thought that sport participation has clear links to mental health and well-being but the sport $c l u b$ does not have the responsibility, mandate or resources to address mental health directly. The sport club does appear valuable in terms of utilising the existing social and support networks among sport parents. For example, parents can promote a mental health intervention within their social networks potentially reaching a greater number of parents, including those that would otherwise not have become involved. Intervention content could also build on the supportive relationships sport parents share with each other. Interestingly, due to the nature/organisation of community sport clubs, many 
563

564

565

566

567

568

569

570

571

572

573

574

575

576

577

578

579

580

581

582

583

584

parents reported being involved in a volunteer capacity, including as coaches. Therefore, targeting parents in a community sports club may have the dual effect of educating coaches and club officials, potentially expanding the benefits of mental health promotion to more adolescent athletes. With increased awareness and exposure, influential others in the sport club could also develop more favourable and proactive attitudes to receiving mental health education.

\section{Conclusion}

This qualitative study provides important information for the development of a mental health intervention for parents of adolescents. Findings indicate that parents had low levels of mental health literacy and wanted information and education on mental health. The current study also revealed important information on the potential role of sport in mental health intervention. Parents discussed the benefits and limitations of using sport and sporting clubs in mental health promotion and disorder prevention. Finally, parents commented on the factors which could facilitate or limit intervention participation and effectiveness. An important direction for future research is to design, implement and examine the feasibility and effectiveness of mental health interventions in sports clubs. Researchers might also look to investigate the views of other key members of community sporting clubs, such as coaches, managers and officials involved in the running of the club (e.g. Club President), as well as the athletes themselves, on the role of the sport club in mental health promotion. The support of these key members is integral to the successful integration of positive mental health practices within community sport clubs. 


\section{References}

586

587

588

589

590

591

592

593

594

595

596

597

598

599

600

601

602

603

604

605

606

607

608

Australian Bureau of Statistics, 2012. Sports and physical recreation: A statistical overview. Canberra, Australia

Australian Institute of Health and Welfare, 2011. Young Australians: their health and wellbeing. Canberra, Australia.

Boulter, E., and Rickwood, D., 2013. Parents' experience of seeking help for children with mental health problems. Advances in mental health, 11(2), 131-142.

Bradley, J., Keane, F., and Crawford, S., 2013. School sport and academic achievement. Journal of School Health, 83, 8-13. doi: 10.1111/j.1746-1561.2012.00741.x

Braun, V., and Clarke, V., 2006. Using thematic analysis in psychology. Qualitative research in psychology, 3(2), 77-101.

Burns, J. R., \& Rapee, R. M. (2006). Adolescent mental health literacy: Young people's knowledge of depression and help seeking. Journal of adolescence, 29(2), 225-239.

Carless, D., and Douglas, K., 2008. Social Support for and Through Exercise and Sport in a Sample of Men with Serious Mental Illness. Issues in Mental Health Nursing, 29(11), 1179-1199. doi: 10.1080/01612840802370640

Carless, D., and Sparkes, A. C., 2008. The physical activity experiences of men with serious mental illness: Three short stories. Psychology of sport and exercise, 9(2), 191-210.

Chandra, A., and Minkovitz, C. S., 2006. Stigma starts early: Gender differences in teen willingness to use mental health services. Journal of Adolescent Health, 38(6), 754.e1-754.e8. doi:10.1016/j.jadohealth.2005.08.011

Cohen, E., Calderon, E., Salinas, G., SenGupta, S., and Reiter, M., 2012. Parents' Perspectives on Access to Child and Adolescent Mental Health Services. Social Work in Mental Health, 10(4), 294-310. doi:10.1080/15332985.2012.672318 
609 Cohen, L., Manion, L., and Morrison, K., 2007. Research methods in education (6th Edition).

610

611

612

613

614

615

616

617

618

619

620

621

622

623

624

625

626

627

628

629

630

631

632

633 London: Routledge.

Costello, E.J., Egger, H., and Angold, A., 2005. 1-year research update review: The epidemiology of child and adolescent psychiatric disorders: I. Methods and public health burden. Journal of the American Academy of Child and Adolescent Psychiatry, 44, 972-986.

Creswell, J. W., 2009. Research design: Qualitative and mixed methods approaches. London: SAGE

Creswell, J. W., and Miller, D. L., 2000. Determining validity in qualitative inquiry. Theory into practice, 39(3), 124-130.

Dempster, R., Wildman, B. and Keating, A., 2013. The role of stigma in parental helpseeking for child behavior problems. Journal of Clinical Child \& Adolescent Psychology, 42(1), 56-67.

Donovan, R. J., Henley, N., Jalleh,G., Silburn, S., Zubrick, S. and Williams, A., 2006. “The Impact of Mental Health in Others of Those in a Position of Authority: A Perspective of Parents, Teachers, Trainers, and Supervisors.” Australian e-Journal for the Advancement of Mental Health, 5(1), 60-66.

Dorsch, T.E., et al., 2016. The impact of evidence-based parent education in organized youth sport: a pilot study. Journal of Applied Sport Psychology. doi:http://dx.doi.org/10.1080/10413200.2016.1194909

Eime, R. M., Young, J. A., Harvey, J. T., Charity, M. J., and Payne, W. R., 2013. A systematic review of the psychological and social benefits of participation in sport for children and adolescents: Informing development of a conceptual model of health through sport. The International Journal of Behavioral Nutrition and Physical Activity, 10, 1-21. doi: 10.1186/1479-5868-10-98 
634 Fredricks, J. A., and Eccles, J. S., 2005. Family socialization, gender, and sport motivation

635

636 and involvement. Journal of Sport and Exercise Psychology, 27, 3-31.

Friars, P., and Mellor, D., 2009. Drop-out from parenting training programmes: A retrospective study. Journal of Child \& Adolescent Mental Health, 21, 29-38.

Fritz, G. K., 2007. Stigma and childhood mental illness: Can advocates turn the tide? Brown University Child \& Adolescent Behavior Letter, 23(11), 8-8.

Geertz, C., 1973. The interpretation of cultures: Selected essays (Vol. 5019). Basic books.

Gonzalez, J. M., Alegria, M., and Prihoda, T. J., 2005. How do attitudes toward mental health treatment vary by age, gender, and ethnicity/race in young adults? Journal Of Community Psychology, 33(5), 611-629. doi:10.1002/jcop.20071

Guba, E.G. and Lincoln, Y.S., 1994. Competing paradigms in qualitative research. Handbook of qualitative research, 2,163-194.

Gulliver, A., Griffiths, K. M., and Christensen, H., 2010. Perceived barriers and facilitators to mental health help-seeking in young people: a systematic review. BMC psychiatry, 10(1), 113. doi: 10.1186/1471-244X-10-113

Hart, L.M., Mason, R.J., Kelly, C.M., Cvetkovski, S., and Jorm, A.F., 2016. 'Teen Mental Health First Aid': a description of the program and an initial evaluation. International Journal of Mental Health Systems, 10 (3), 1-18. doi:http://dx.doi. org/10.1186/s13033-016-0034-1.

Harwood, C., Drew, A., and Knight, C. J., 2010. Parental stressors in professional youth football academies: A qualitative investigation of specialising stage parents. Qualitative research in sport and exercise, 2(1), 39-55.

Harwood, C. G., and Knight, C. J., 2015. Parenting in youth sport: A position paper on parenting expertise. Psychology of sport and exercise, 16, 24-35. 
Hefferon, K., Mallery, R., Gay, C., and Elliott, S., 2013. 'Leave all the troubles of the outside world': a qualitative study on the binary benefits of 'Boxercise'for individuals with mental health difficulties. Qualitative research in sport, exercise and health, 5(1), 80-102.

Henley, N., Williams, A., Silburn, S.R., Donovan, R.J., Zubrick, S.R. and Jalleh, G., 2007. People's beliefs about factors contributing to mental health: implications for mental health promotion. Health promotion journal of Australia: official journal of Australian Association of Health Promotion Professionals, 18(1), 50.

Jorm, A. F., Korten, A. E., Jacomb, P. A., Christensen, H., Rodgers, B., and Pollitt, P., 1997.Mental health literacy: a survey of the public's ability to recognise mental disorders and their beliefs about the effectiveness of treatment. Medical Journal of Australia, 166(4).

Jorm, A. F., Wright, A., and Morgan, A. J., 2007. Beliefs about appropriate first aid for young people with mental disorders: findings from an Australian national survey of youth and parents. Early Intervention in Psychiatry, 1(1), 61-70.

Jorm, A.F. and Wright, A., 2007 Beliefs of young people and their parents about the effectiveness of interventions for mental disorders. Australian and New Zealand Journal of Psychiatry, 41, 656-666.

Jorm, A.F., 2012. Mental Health Literacy: Empowering the Community to Take Action for Better Mental Health. American Psychologist, 67 (3), 231-243.

Kessler, R. C., Berglund, P., Demler, O., Jin, R., Merikangas, K. R., and Walters, E. E., 2005. Lifetime Prevalence and Age-of-Onset Distributions of DSM-IV Disorders in the National Comorbidity Survey Replication. Archives of General Psychiatry, 62(6), 593-602. doi: 10.1001/archpsyc.62.6.593 
682

683

684

685

686

687

688

689

690

691

692

693

694

695

696

697

698

699

700

701

702

703

704

Kuhn, E. S., and Laird, R. D., 2014. Family support programs and adolescent mental health: review of evidence. Adolescent Health, Medicine and Therapeutics, 5, 127-142. doi:10.2147/AHMT.S48057

Lawrence, D., Johnson, S., Hafekost, J., Boterhoven De Haan, K., Sawyer, M., Ainley, J., and Zubrick, S.R., 2015. The Mental Health of Children and Adolescents. Report on the second Australian Child and Adolescent Survey of Mental Health and Wellbeing. Department of Health, Canberra.

Liddle, S.K., Deane, F.P. and Vella, S.A., 2016. Addressing mental health through sport: a review of sporting organizations' websites. Early intervention in psychiatry. doi: 10.1111/eip.12337.

Logan, D. E., and King, C. A., 2001. Parental facilitation of adolescent mental health service utilization: A conceptual and empirical review. Clinical Psychology: Science and Practice, 8(3), 319-333.

Mason, R. J., Hart, L. M., Rossetto, A., and Jorm, A. F., 2015. Quality and predictors of adolescents' first aid intentions and actions towards a peer with a mental health problem. Psychiatry Research, 228(1), 31-38. doi:10.1016/j.psychres.2015.03.036

Maykut , P. and Morehouse , R., 1994. Beginning qualitative research: a philosophic and practical guide. Lewes: Falmer Press.

Mazzer, K. R., and Rickwood, D. J., 2015. Mental health in sport: coaches' views of their role and efficacy in supporting young people's mental health. International Journal of Health Promotion and Education, 53(2), 102-114. 
Mazzer, K. R., and Rickwood, D. J., 2013. Community-based roles promoting youth mental health: comparing the roles of teachers and coaches in promotion, prevention and early intervention. International Journal of Mental Health Promotion, 15(1), 29-42.

Mazzer, K. R., Rickwood, D. J., and Vanags, T., 2012. Teachers and sports coaches supporting young people's mental health: promotion, prevention, and early intervention. World Academy of Science, Engineering and Technology, 66, 489-494.

Mendenhall, A. (2012). Predictors of Service Utilization Among Youth Diagnosed with Mood Disorders. Journal of Child \& Family Studies, 21(4), 603-611. doi:10.1007/s10826-011-9512-x

Mendenhall, A. N., and Frauenholtz, S., 2015. Predictors of mental health literacy among parents of youth diagnosed with mood disorders. Child \& Family Social Work, 20(3), 300-309. doi:10.1111/cfs.12078

Merkel, D.L., 2013. Youth sport: Positive and negative impact on young athletes. Open Access J Sports Med, 4, 151-160.

Morgan, A.J. and Jorm, A.F., 2008. Self-help interventions for depressive disorders and depressive symptoms: a systematic review. Annals of general psychiatry, 7(1), 1.

Offer, D., Howard, K.I., Schonert, K.A. and Ostrov, E., 1991. To whom do adolescents turn for help? Differences between disturbed and nondisturbed adolescents. Journal of the American Academy of Child \& Adolescent Psychiatry, 30(4), 623-630

Onwuegbuzie, A. J., Dickinson, W. B., Leech, N. L., and Zoran, A. G., 2009. A qualitative framework for collecting and analyzing data in focus group research. International journal of qualitative methods, 8(3), 1-21.

Perry, B.R., Pescosolido, B.A., Martin, J.K., McLeod, J.D. and Jensen, P.S., 2007. Comparison of public attributions, attitudes, and stigma in regard to depression among children and adults. Psychiatric Services, 58 (5), 632-635. 
Pescosolido, B.A., Jensen, P.S., Martin, J.K., Perry, B.L., Olasfsdottir, S. and Fettes, D., 2008. Public knowledge and assessment of child mental health problems: findings from the National Stigma Study-Children. Journal of the American Academy of Child and Adolescent Psychiatry, 47, 339-349.

Pierce, D., Liaw, S. T., Dobell, J., and Anderson, R. J., 2010. Australian rural football club leaders as mental health advocates: An investigation of the impact of the Coach the Coach project. International Journal of Mental Health Systems, 4(1), 10-10. doi: $10.1186 / 1752-4458-4-10$

Reavley, N.J. and Jorm, A.F., 2011. Stigmatizing attitudes towards people with mental disorders: findings from an Australian National Survey of Mental Health Literacy and Stigma. Australian and New Zealand Journal of Psychiatry, 45(12), 1086-1093.

Rickwood, D. J., Deane, F. P., Wilson, C. J., and Ciarrochi, J., 2005. Young People's Helpseeking for Mental Health Problems. Australian e-Journal for the Advancement of Mental Health, 4(3), 218-251.

Rickwood, D. J., Deane, F. P., and Wilson, C. J., 2007. When and how do young people seek professional help for mental health problems? Medical Journal of Australia, 187(7 (Suppl)), S35-S39.

Sanders, M. R., 2002. Parenting interventions and the prevention of serious mental health problems in children. Medical Journal of Australia, 177(7), S87.

Sayal, K., Tischler, V., Coope, C., Robotham, S., Ashworth, M., Day, C., Tylee, A. and Simonoff, E., 2010. Parental help-seeking in primary care for child and adolescent mental health concerns: qualitative study. The British Journal of Psychiatry, 197(6), 476-481.

Shenton, A. K. (2004). Strategies for ensuring trustworthiness in qualitative research projects. Education for information, 22(2), 63-75. 
Snell-Johns, J., Mendez, J.L., and Smith, B.H., 2004. Evidence-based solutions for overcoming access barriers, decreasing attrition, and promoting chance with underserved families. Journal of Family Psychology, 18,19-35.

Sparkes, A. C., and Smith, B., 2013. Qualitative research methods in sport, exercise and health: From process to product. Routledge.

Spencer, L., Ritchie, J., Lewis, J., and Dillon, L. 2003. Quality in qualitative evaluation: A framework for assessing research evidence. London: National Centre for Social Research, Government Chief Social Researcher's Office, UK.

Srivastava, P., and Hopwood, N., 2009. A practical iterative framework for qualitative data analysis. International journal of qualitative methods, 8(1), 76-84.

Tamminen, K. A., and Holt, N. L., 2012. Adolescent athletes' learning about coping and the roles of parents and coaches. Psychology of sport and exercise, 13(1), 69-79.

Teagle, S.E., 2002. Parental problem recognition and child mental health service use. Mental Health Services Research, 4 (4), 257-266.

Tremblay, M.S., Gray, C.E., Akinroye, K.K., Harrington, D.M., Katzmarzyk, P.T., Lambert, E.V., Liukkonen, J., Maddison, R., Ocansey, R.T., Onywera, V. and Prista, A., 2014. Physical activity of children: a global matrix of grades comparing 15 countries. Journal of physical activity and health, 11(Supp 1), 113-125.

Vella, S. A., Cliff, D. P., Magee, C. A., and Okely, A. D., 2015. Associations between sports participation and psychological difficulties during childhood: A two-year follow up. Journal of Science and Medicine in Sport, 18(3), 304-309. doi: 10.1016/j.jsams.2014.05.006

Verhulst, F. C., and Van Der Ende, J. A. N., 1997. Factors associated with child mental health service use in the community. Journal of the American Academy of Child \& Adolescent Psychiatry, 36(7), 901-909. 
780

781

782

783

Wang, J., and Lai, D., 2008. The relationship between mental health literacy, personal contacts and personal stigma against depression. Journal of affective disorders, 110(1), 191-196.

Wiersma, L. D., and Fifer, A. M., 2008. "The Schedule Has Been Tough But We Think It's Worth It": The Joys, Challenges, and Recommendations of Youth Sport Parents. Journal of leisure research, 40(4), 505.

World Health Organisation, 2005. Caring for children and adolescents with mental disorders: setting WHO directions. Geneva, World Health Organization.

World Health Organization, 2012. .Adolescent mental health. Geneva: WHO Press. 
Table 1: Thematic analysis codes, themes and categories

Codes Higher order themes Descriptive categories

Previous experience with mental health and help seeking

Visibility/exposure/awareness

Availability and access

Type of help/help provider

Benefits of seeking help

Perceptions of seeking help

Time differences

Parent responsibility

Need recognition

Fear/concern about mental health disorders

How to tell?

What is normal?

disorders

How to tell?

What to do?

Where to go?

Coping strategies/well-being strategies

Lessons/skills learned through sport

Social network

Social support

Parent to parent communication

Relationship between sport and health

Role/responsibility of sport club

Sport environment/culture

Coach-athlete relationship

Parent-coach communication

Responsibilities and boundaries

Training and education

What to do?

community

Role of coach
Experience with and exposure

to mental health

Attitudes to seeking help

Stigma

Need recognition
Experience with and exposure to mental health

Mental health education and information

How to communicate

Normalising discussion around mental health Addressing parent needs

Giving options/choice

Simplicity

The value of sport

The sports club as a

Dealing with mental health disorders

Using sport/social networks

Accessibility

Reaching and engaging

Barriers and facilitators to sports

Mixed methods

parents

Role of sport in family life and mental health

Role of sport in mental health

Place

Time

Convenience

Barriers 


\section{Appendix A}

\section{Discussion Guide}

Family dynamics and beliefs about 'mental health '

- What sort of things do you talk about as a family?

- What comes to mind when I say 'mental health' - what do you think this means?

- Do you and your family talk about mental health?

o Why/Why not?

\section{Knowledge and attitudes to adolescent mental health and help seeking}

- Do you know what things are recommended to improve or maintain your well-being?

- Do you know what things are recommended when people are feeling stressed/anxious/depressed?

- How would you feel if your son were really stressed, depressed or anxious?

- What would you do?

- Can you think of any things in terms of information or services that you can currently access in relation to mental health?

- Do you think it would be useful to have more information about how to support your son's mental health and well-being? Why or why not?

○ What kinds of things would you like to know about?

\section{Role of sport in mental health}

- What do you think is the role of the sports club in promoting mental health for your son?

- How would you feel if your adolescent son sought help or advice from another source?

- Do you think coaches and/or managers know about mental health issues like stress, depression and anxiety?

○ Do you think they should know? What do you think they know?

- What would you want the coach or manager to do if they noticed that your son may need some help regarding their mental health?

\section{Barriers and facilitators to being involved in a parenting/family program}

- Can you think of any ways that might encourage you to learn more about how you can support your son's mental health?

- What about sport/your sports club? Would it be a good place?

- What could we do to make it easy for you as parents to participate in a program that helps you support your son's mental health?

- What would encourage you to participate in a family/parenting program?

○ Content - what would you like to learn about? What kind of activities would you like to do?

○ Delivery - how would you like the course delivered?

- Length - how long would it go for?

- Information - how would you find out about it?

- Suggestions for specific components/formats 